retical amount of sulfur dioxide was evolved, and the mixture may be heated to fusion without much further loss of sulfur dioxide.

A more rapid reaction occurs according to the second of the above equations when silver sulfite is heated in the presence of water. ${ }^{1}$ It is evident that in the reaction as written the water can take no part except as a catalyzer. When a mixture of silver sulfite and water was heated to $I \mathrm{IO}^{\circ}$ in a tube connecting with a manometer, the partial pressure of sulfur dioxide reached 4 atmos. But when the tube was heated to $132^{\circ}$ this partial pressure fell to less than 3 atmos. This surprising result was not understood until further investigation showed that when the system is heated at constant temperature the pressure rises rapidly to a maximum and then falls off, apparently without limit, according to the law of a monomolecular reaction. This effect is in all probability due to the simultaneous occurrence of two independent reactions, the first of which we have no reason to doubt is the one written above. The second reaction we believe to be

$$
\mathrm{Ag}_{2} \mathrm{SO}_{4}+\mathrm{SO}_{2}+2 \mathrm{H}_{2} \mathrm{O}=2 \mathrm{Ag}+2 \mathrm{H}_{2} \mathrm{SO}_{4} \text {. }
$$

In fact an analysis of the mixture showed the presence of sulfuric acid. This reaction is quite analogous to the corresponding one with mercurous sulfate, which we shall discuss at length in another paper. It seems very likely that it might be possible to separate these two reactions and obtain true equilibrium conditions in the former, but we have not proceeded further in these directions.

The various reactions which have been chosen for detailed study will be discussed in other papers. In the present group will be included two papers on the reactions of sulfur dioxide, and one on the free energy of dilution of sulfuric acid, while in a later group, which we hope to publish in the near future, we shall include papers involving the free energy of formation of sulfuric acid and finally a general paper on the free energy of the sulfur compounds.

BERKELEY, CAL.

[CONTRIBUTION FROM THE Chemical LABORATORY OF THE UNIVERSity OF CaLIFornia.]

\title{
EQUILIBRIUM IN THE REACTION BETWEEN WATER AND SULFUR AT THE BOILING POINT OF SULFUR. ${ }^{2}$
}

By Gilbert N. I.ewis and Merle Randall.

Received October 16,1917.

The well-known reaction between gaseous hydrogen sulfide and sulfur dioxide to give sulfur and water has been studied by numerous investi-

This reaction is mentioned in Abegg's Handbuch, 1,714 .

2 This work was carried out in the Research Laboratory of Physical Chemistry of the Massachusetts Institute of Technology, and concluded in Igro. 
gators, ${ }^{1}$ and their work indicates the probable reversibility of the reaction. Preliminary experiments at about $500^{\circ}$ showed this to be the case, the reaction $2 \mathrm{H}_{2} \mathrm{O}+{ }_{3} \mathrm{~S}=2 \mathrm{H}_{2} \mathrm{~S}+\mathrm{SO}_{2}$ occurring rapidly in either direction according to the conditions imposed. In fact the rapidity of the reaction precludes the use of the method of determining the equilibrium by rapidly cooling the reacting substances and analyzing. The only practicable method which suggested itself depends upon the fact that, owing to a change in the number of mols during the reaction, there should be a corresponding pressure change. If the experiments are made in the presence of an excess of liquid sulfur, the other substances being in the gaseous state, the pressure of the other substances would be increased by one-half if the water were completely converted into hydrogen sulfide and sulfur dioxide. Since, however, under the conditions of our experiments the fraction of water which reacts is small, we have been obliged to scrutinize with unusual caution every possible source of error in the pressure measurements.

The apparatus (Fig. I) consisted essentially of a glass reaction bulb, A, of about I75 cc. ca pacity, connected through the capillary tube $\mathrm{D}$ to the open manometer M. The level of the mercury in the short arm of the manometer could always be brought to the mark $E$, close to the end

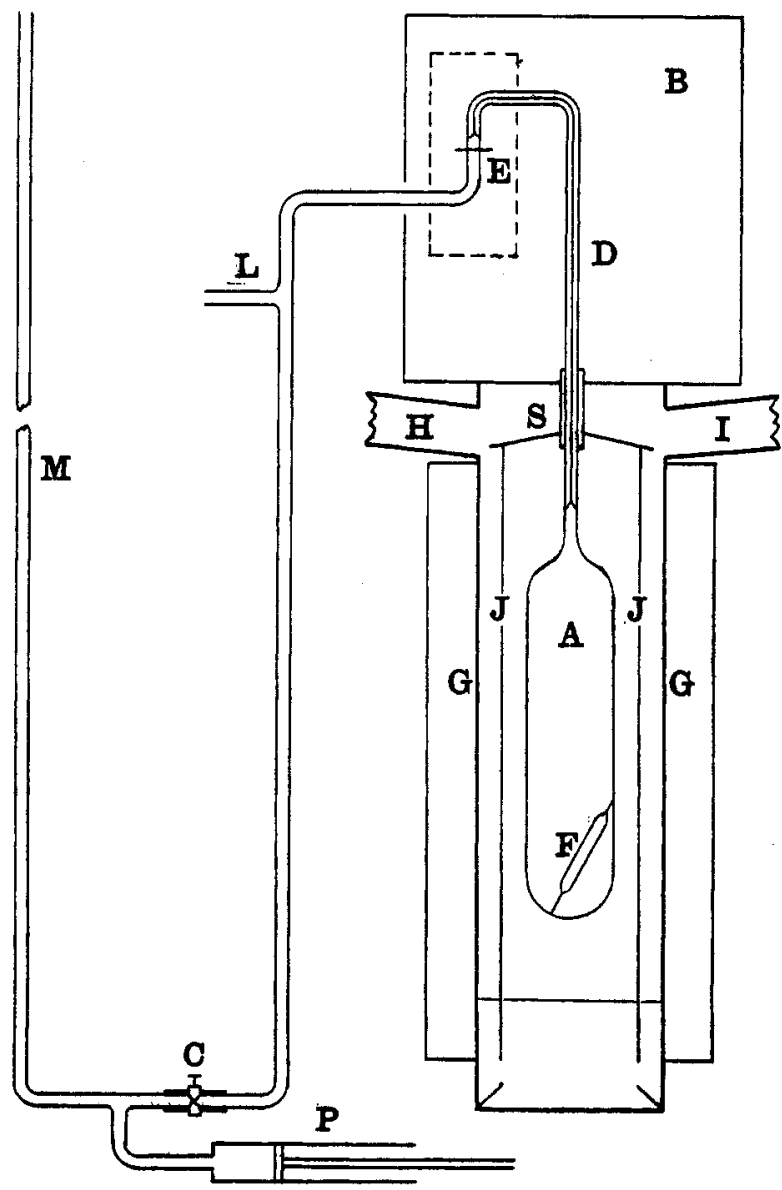

Fig. I.

${ }^{1}$ Mulder, Jahresb., 1856, 86; Corenwinder, Compt. rend., 53, I40 (186I); Gripon, Ibid., 56, I37 (1863); Meyers, J. prakt. Chem., I08, I23 (1869); Meyers, Compt. rend., 74, $195(1872)$. 
of the capillary D, by means of the cylinder and piston $P$. The level of the mercury could be lowered and the tube A exhausted through the side tube $L$, by means of a Toepler pump not shown in the figure. The screw clip $C$, operating on a small section of rubber tubing, served to control the flow of mercury in the manometer tubes during the adjustment of the pressures, but was always left open during the final readings.

The reaction tube $A$ was heated by means of a bath. of sulfur vapor. This vapor bath was made of a piece of steel pipe GG, $10 \mathrm{~cm}$. in diameter and $48 \mathrm{~cm}$. long, with a bottom piece welded in. Near the top two pieces of iron pipe $\mathrm{H}$ and $\mathrm{I}$, about $2.5 \mathrm{~cm}$. in diameter and $20 \mathrm{~cm}$. long, were screwed in and served as condensers. These condenser tubes were given a slight grade. The top of the bath was turned off square in a lathe and was raised against an asbestos washer on the bottom of the sheet iron box B. A steel tube, JJ, about $6 \mathrm{~cm}$. in diameter and flanged at the bottom, was held in the middle of the heater. The annular space between the tubes $\mathrm{G}$ and $\mathrm{J}$ formed a vapor jacket around the inner tube, inside which the reaction tube $A$ was placed. The inverted mica cone $S$ was fastened to the tube $A$ by means of asbestos twine and prevented the cooler condensed sulfur from dripping upon this tube. The opening between the box $B$ and the sulfur bath, through which the capillary $D$ passed, was closed by a packing of asbestos cord. The sides of the bath were well jacketed with magnesia asbestos lagging. The bath was supported upon a heavy iron tripod, and heated by gas.

The sheet iron box $\mathrm{B}$, lined with asbestos, and provided with a mica window in front of the reference mark $\mathrm{E}$, surrounded the capillary $\mathrm{D}$. The box was heated by two loo watt lamps which served not only to keep the temperature of the box between $120^{\circ}$ and $145^{\circ}$ but also to illuminate the interior. The purpose of this box was to avoid condensation of water in the capillary.

A small thin-walled glass tube $F$ was drawn down to a fine capillary at both ends, so as to have a volume of $0.04-0.06 \mathrm{cc}$. Boiled distilled water was then introduced and the ends so sealed that no air and a very small vapor space remained. The bulb would then explode when slightly heated. This bulb was weighed empty and after sealing. ${ }^{1}$ The volume of the reaction tube $A$ was determined by weighing the bulb empty, and filled with water. A weighed quantity, $2-4 \mathrm{~g}$., of pure sulfur, in the form of a fine powder, was introduced into the tube with the sealed glass bulb containing the water. The reaction tube was then sealed to the capillary (D) and the cold vapor bath raised into its position beneath the box $B$. The level of the mercury was brought below $L$ and the reaction tube exhausted. The connection to the pump was sealed off, and the level of

${ }^{\prime}$ A balance sensitive to $0.00003 \mathrm{~g}$. was used. The mean of several readings was taken in each case. 
the mercury brought back to the reference mark $\mathrm{E}$ and the screw clip $\mathrm{C}$ closed.

The vapor bath was heated gradually, and then the lights in the box $B$ were turned on. ${ }^{1}$ As the temperature of the bath reached equilibrium, the height of the manometer was adjusted by manipulating the screw clip $\mathrm{C}$ and the piston $\mathrm{P}$ so as to keep the mercury at the reference point $\mathrm{E}$. When the pressure in the bulb $\mathrm{A}$ had reached equilibrium, the barometric height was noted and the height of the mercury column in $M$ above the reference mark $\mathrm{E}$ was determined.

Owing to the difficulty of the manipulations, a number of experiments were fruitless, but satisfactory measurements were made in six experiments, and the results are given in Table $I$. The first two columns give the weight in $\mathrm{g}$. of water and of sulfur, the third gives the corrected volume of the reaction tube. The corrections include the expansion of glass, the volume of the sulfur left unvolatilized, of the fragments of the glass bulb which contained the water, and the volume of the capillary and connecting tube, which was always less than $0.1 \mathrm{cc}$. The fourth column gives the barometric pressure, and the last the observed pressure of the equilibrium mixture in millimeters.

\begin{tabular}{ccccc} 
H.O. & \multicolumn{5}{c}{ TABLE I. } \\
0.04410 & S. & Cor. vol. & Bar. Mm. & P. \\
0.05492 & $3.8 \mathrm{I}$ & I50.8 & 77 I & I554 \\
0.05214 & 2.24 & 203.6 & 76 I & 1476 \\
0.05882 & 2.02 & 152.3 & 756 & 1656 \\
0.04702 & 2.27 & 202.8 & 758 & 1538 \\
0.05402 & 2.55 & I66.7 & 766 & I5I9 \\
& I.75 & II 7.2 & 764 & 1978
\end{tabular}

Since the reaction chamber is surrounded by the vapor of boiling sulfur the vapor pressure of sulfur within the chamber should be identical with the barometric pressure. Therefore by subtracting the barometric pressure from the observed pressure we should be able to find the combined pressure of the three gases, steam, sulfur dioxide and hydrogen sulfide, and, by comparing this with the pressure calculated from the amount of water introduced, calculate the extent to which the reaction had occurred. Fortunately, before making this calculation it was decided to make certain incidental experiments which showed the existence of a small but appreciable error. First, experiments of the same character as those which we have described were made in the absence of sulfur. Two experiments of this type are reproduced in Table II in which the first column.gives the weight of water introduced, the second the corrected volume of the bulb,

1 These lights were turned on at such a time that the oven would come to about $130^{\circ}$ a short time before the bulblet containing the water exploded. If the box $B$ were heated for too long a time mercury would distil gradually into the tube $D$. 
the third the observed pressure, and the fourth the pressure which would be calculated from the gas law.

TABLE II.

$\begin{array}{cccc}\mathrm{H}_{2} \mathrm{O} . & \text { Cor. vol. } & \text { pobs. } & \text { palc. } \\ \text { c. } 05873 & 152.4 & 96 \mathrm{I} & 957 \\ 0.0778 \mathrm{I} & 183.2 & 1058 & 1055.5\end{array}$

The difference, which amounts to $4 \mathrm{~mm}$. in the first case and $2.5 \mathrm{~mm}$. in the second, seemed larger than could be accounted for at this temperature by a deviation from the gas law. This suggested the possibility that the excess pressure was due to adsorbed water which remained upon the surface of the reaction tube after prolonged exhaustion. This seemed the more likely, since it was impossible, owing to the conditions of the experiment, to heat the reaction tube during the preliminary exhaustion. This assumption was tested by another experiment in which neither water nor sulfur was put into the tube. A glass tube with a volume of $84 \mathrm{cc}$. was cleaned and washed as in the previous experiments, and after prolonged exhaustion as before, the pump was sealed off and the sulfur bath was raised into position and heated, the box $B$ being left cold. The pressure rose at once to $5 \mathrm{~mm}$. and remained constant as long as the heating was continued, but when the apparatus was cooled the pressure once more fell to zero. This seems to prove conclusively that there is enough adsorbed water upon the glass container to produce a pressure of several $\mathrm{mm}$. at the boiling point of sulfur. The pressure in the experiment just described was greater than that deduced from the two experiments of Table II, since in this case a smaller glass tube was used, and the ratio of surface to volume was therefore larger.

This assumption of the existence of adsorbed water was further confirmed by two experiments in which sulfur, in sufficient amount to remain unvaporized at $445^{\circ}$, was heated in a tube of about $\mathrm{I} 5 \mathrm{O} \mathrm{cc}$. in the absence of water. However, the sulfur could not be heated alone in the apparatus for it would then pass into the capillary tube and condense, or react with the mercury. For this reason a small amount of air was left in the tube to prevent the rapid diffusion of sulfur into the capillary. In the first column of Table III is given the initial pressure of the air, in the second the initial temperature, in the third the barometric pressure, in the fourth the observed pressure, and in the fifth the pressure calculated by adding to the barometric pressure the calculated pressure of the air. The transformation of some of the oxygen of the air into sulfur dioxide should not change the pressure, since one mol of oxygen gives one mol of sulfur dioxide.

TABLE III.

$\begin{array}{ccclc}\text { Init. press. } & \text { Init. temp. } & \text { Bar. } & \text { pobs. } & \text { pcalc. } \\ 93 & 26 & 767 & 996 & 991 \\ 6.3 & 26 & 757 & 776.5 & 772\end{array}$


Here again in the difference between the calculated and observed pressures we see the effect of the adsorbed water. These experiments show further that the sulfur itself gives off no appreciable amount of gas when heated.

In order to allow for the small effect of the adsorbed water, we have added $4 \mathrm{~mm}$. to the calculated pressure of the water vapor in all of the experiments of Table I. We may now proceed to the final calculation of these results. In Table IV the first column gives the observed pressure, the second the partial pressure of the sulfur and of the water calculated from the gas law with the slight correction which we have just indicated. The third column gives the difference between Cols. I and 2. If this difference represents the extent of the reaction in which two mols of water disappear and two mols of hydrogen sulfide and one of sulfur dioxide are formed, it is equal to the partial pressure of sulfur dioxide and one-half the partial pressure of hydrogen sulfide. These are given in Cols. 3 and 4 . The fifth column shows the barometric pressure, which is the partial pressure of sulfur vapor. The partial pressure of the water vapor is equal to the total pressure less the partial pressures of the other three gases. This is given in the sixth column. All these pressures have been given in millimeters, but it is customary to express the final value of the equilibrium constant in atmospheres. We have therefore reduced the values to this unit, and the seventh column gives the values of $\mathrm{K}_{p}=\left[\mathrm{H}_{2} \mathrm{~S}\right]^{2}\left[\mathrm{SO}_{2}\right] /\left[\mathrm{H}_{2} \mathrm{O}\right]^{2}$.

TABLE IV.

\begin{tabular}{|c|c|c|c|c|c|c|}
\hline $\begin{array}{l}\text { Dobs. } \\
\text { Mmen. }\end{array}$ & $\begin{array}{l}P_{\text {calc. }} \\
\text { Mm. }\end{array}$ & $\begin{array}{c}p \mathrm{SO}_{2} . \\
\mathrm{Mm} .\end{array}$ & $\begin{array}{l}p \mathrm{H}_{2} \mathrm{~S} . \\
\mathrm{Mm} .\end{array}$ & $\begin{array}{l}p \mathrm{~S} . \\
\text { Mm. }\end{array}$ & $\begin{array}{l}p \mathrm{H}_{2} \mathrm{O} . \\
\mathrm{Mm} .\end{array}$ & $\begin{array}{c}\mathbf{K}_{p} \\
\text { Atmos. }\end{array}$ \\
\hline I 554 & I 501 & 53 & 106 & $77 \mathrm{I}$ & 624 & 0.00201 \\
\hline 1476 & I 435 & $4 \pi$ & 82 & $76 \mathrm{I}$ & 592 & 0.00105 \\
\hline 1656 & I6Io & 46 & 92 & 756 & 762 & 0.00088 \\
\hline I 538 & 1483 & 55 & I IO & $75^{8}$ & 615 & 0.00232 \\
\hline 1519 & I $47 \mathrm{I}$ & 48 & 96 & 766 & 609 & 0.00157 \\
\hline I 978 & I9I3 & 65 & 130 & 764 & 1019 & 0.00139 \\
\hline
\end{tabular}

Considering the unusual magnification of the errors in obtaining $\mathrm{K}_{p}$ the results, which show an average deviation from the mean of $28 \%$, may be regarded as quite satisfactory. We shall take as final value, the average, namely, $K_{p}=0.00154$, and shall show in another paper how this value may be used in the calculation of the free energy of formation sulfur dioxide. 